\title{
Balancing Afforestation with Grain Production and Water Use for Sustainable Effects of Soil Conservation in the Chinese Loess Plateau
}

\section{MATSUNAGA Kohei}

Graduate School of Media and Governance, Keio University; Kanagawa 252-0882, Japan.

E-mail: matunaga@sfc.keio.ac.jp

Received July 31, 2014; Accepted February 26, 2015

Abstract The Chinese Loess Plateau experiences the most severe soil erosion in the world, induced by the destruction of natural vegetation for cultivation. To stop soil erosion, in 1999 the Chinese government began an intensive afforestation program named Grain-for-Green-Policy in order to convert steep cultivated land to forest and grassland. Balancing afforestation with grain production and water use is crucial for obtaining sustainable effects of soil conservation. This study assessed the current balance among afforestation, grain production, and water use in river basins on the Chinese Loess Plateau. Annual afforested area, planted area of grain fields, precipitation, and irrigated area in these river basins were compared based on the data collected from the statistical yearbooks of the Yan'an City. River discharge and sediment yield in the areas were compared based on data collected from the Annual Report on Chinese Soil Conservation. The evapotranspiration rates of the main crops cultivated in each river basin were also compared. Collectively, the data suggest that the balance between afforestation, grain production, and water use has been improved by the Grain-for-Green-Policy in the river basins on the Chinese Loess Plateau.

Key words Afforestation, Grain production, Water use, Soil conservation, Chinese Loess Plateau

\section{Introduction}

The Chinese Loess Plateau, located in the middle reaches of the Yellow river basin, suffers from the most severe soil erosion in the world (Figure 1). The soft loess soil is easily eroded by summer rainfall.

For decades, soil erosion on the Chinese Loess Plateau has been accelerated by deforestation by humans (Shi 2001). The plateau was heavily forested 3,000 years ago, but wars and other human activities in the intervening time have continuously decreased the forested area, leading to soil erosion (Shi 2001).

Since 1999, the Chinese government has been struggling to stop soil erosion with an intensive afforestation program named the Grain-for-Green-Policy, which entails converting steep cultivated land to forest and grassland.

Although the policy has facilitated the successful reduction of soil erosion, the conversion of steep cultivated land to forest and grassland has also dramatically reduced the total grain production in China (Matsunaga 2013). Moreover, as the planted trees grow larger, they consume more water, placing pressure on the limited water resources (Fukushima and Taniguchi 2008).

Therefore, balancing afforestation with grain produc- tion and water is crucial for achieving sustainable effects of soil conservation. However, because the physical environment and human activities differ among river basins, the optimal balance between these three factors needs to be defined separately for each river basin. To this end, we assessed the current balance among afforestation, grain production, and water use in individual river basins on the Chinese Loess Plateau.

\section{Study Area}

Typical river basins included in the Grain-for-GreenPolicy in Shaanxi Province were selected for this study. Two river basins were also chosen from the Yan'an City (Figure 1), where afforestation has been intensively implemented as part of the Grain-for-Green-Policy.

One of the study areas is the Yan river basin(Figure 1). Mean annual precipitation is approximately $500 \mathrm{~mm}$. Steep loess hills named Liang and Mao are distributed in the basin, and soil erosion in these areas occurs due to summer water flow. Since the implementation of the Grain-for-Green-Policy, vegetables have been planted as cash crops instead of grains (Sato et al. 2008).

The other study area is the Luo River basin (Figure 1). Mean annual precipitation is approximately $500 \mathrm{~mm}$. 


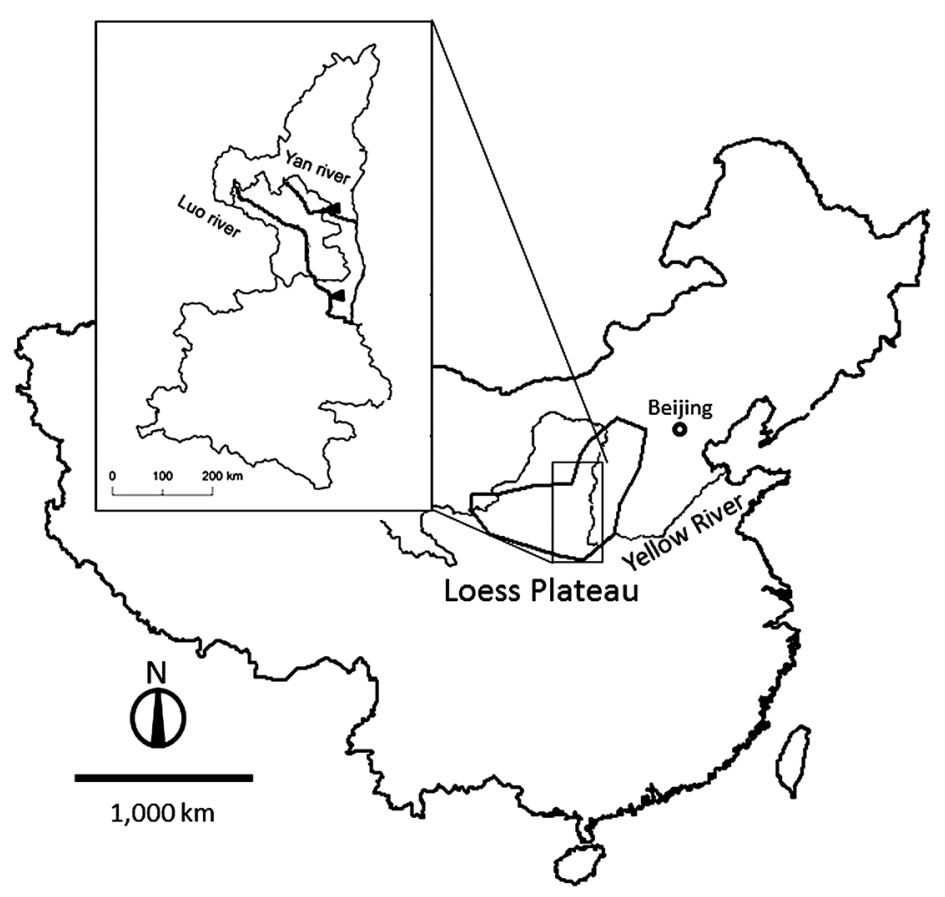

Figure 1. The Chinese Loess Plateau and study areas.

The small rectangle shows the locations of the Shaanxi Province and study areas in the Yan'an City. Black isosceles triangles show the locations of the hydrological observation stations.

Loess hills are distributed in the upper reaches of the Luo river basin. Loess tablelands are distributed in the middle and lower reaches of the Luo river basin, and wheat and maize are planted in flat areas.

\section{Methods}

To assess the balance among afforestation, grain production, and water use from the viewpoint of soil conservation, the annual afforested area, planted area of grain fields, precipitation, and irrigated area in the river basins were compared based on the data collected from the statistical yearbooks of the Yan'an City. River discharge and sediment yield were compared based on data collected from the Annual Report on Chinese Soil Conservation. The total evapotranspiration of the main crops cultivated in the river basins, including wheat, rice, maize, and vegetables, was calculated; the total evapotranspiration of each crop was calculated based on its water requirements (Liu et al. 2007) and its planted area, which is recorded in the statistical yearbooks of Yan'an City.

\section{Results and Discussion}

In the Yan river basin, the balance among afforestation, grain production, and water use was improved by the Grain-for-Green-Policy. Following 1999, when the policy was introduced, the afforested area showed large annual increases until 2004, when afforestation by the policy nearly ceased (Table 1). Although the planted area of grain is approximately 60,000 ha per year in the Yan river basin, the sediment yield (the amount of soil erosion within the basin) has drastically decreased since 2006 . The annual precipitation, input of water resources within the basin, and the river discharge (which represents the residual amount of water resources within the basin) showed no significant decrease after 2006. Thus, afforestation appears to have decreased soil erosion without the depletion of the water resources, although Fukushima and Taniguchi (2008) pointed out that soil-water content reduces as trees grow due to the increasing evapotranspiration rate from the trees. The reason why this soil-water content reduction was not observed here might be that planted trees did not grow larger within the Yan River basin. No clear increasing trend was observed for the total evapotranspiration of the main crops within the basin. Therefore, agriculture also had no significant effect on the basin's water resources.

In the Luo river basin, the implementation of the Grain-for-Green-Policy also appears to have improved the balance among afforestation, grain production, and water use. As observed in the Yan river basin, the afforested area significantly increased following the implementation of the policy in 1999. In contrast, the planted area of grain declined more drastically than the Yan river basin until 2002; however, it remained constant subsequently. 
The sediment yield has decreased since 2006, although precipitation and river discharge showed no significant changes. Therefore, the afforestation promoted by the Grain-for-Green-Policy appears to have protected the soil from erosion. As the total evapotranspiration of the main crops was almost stable, the river discharge showed no significant decline. Thus, as seen in the Yan River basin, the impacts of afforestation and agriculture on the water resources within the Luo river basin remained negligible up to 2008 .
Due to climate change, the probability of extreme events such as drought and flood will increase (Oki and Kanae 2006). Therefore, to ensure food security during drought, irrigation is important. However, there has been no significant increase in the irrigated area from 1994 to 2008 (Tables 1 and 2). The implementation of irrigation should be investigated in future studies to reduce the vulnerability of agriculture in the Loess Plateau to extreme events. Additionally, to maintain soil resources during flooding, maintenance of the afforested area within each

Table 1. The balance among afforestation, grain production, and water use in the Yan river basin

\begin{tabular}{|c|c|c|c|c|c|c|c|}
\hline & $\begin{array}{l}\text { Precipitation } \\
\left(\text { billion } \mathrm{m}^{3} \text { ) }\right.\end{array}$ & $\begin{array}{c}\text { Total ET from } \\
\text { main crops } \\
\text { (billion } \mathrm{m}^{3} \text { ) }\end{array}$ & $\begin{array}{c}\text { Planted area } \\
\text { of grain } \\
\text { (ha) }\end{array}$ & $\begin{array}{c}\text { Afforested area } \\
\text { (ha) }\end{array}$ & $\begin{array}{l}\text { Irrigated area } \\
\text { (ha) }\end{array}$ & $\begin{array}{l}\text { Sediment yield } \\
\text { (billion ton) }\end{array}$ & $\begin{array}{l}\text { Discharge } \\
\text { (billion } \mathrm{m}^{3} \text { ) }\end{array}$ \\
\hline 1994 & 36.579 & 0.076 & 60694.000 & 15960.000 & 6000.000 & \multirow{4}{*}{0.045} & \multirow{4}{*}{0.211} \\
\hline 1995 & 24.398 & 0.107 & 68199.000 & 20520.000 & & & \\
\hline 1998 & 33.646 & 0.100 & 66937.000 & 20840.000 & & & \\
\hline 1999 & 21.803 & 0.093 & 65598.000 & 27280.000 & & & \\
\hline 2000 & 22.768 & 0.074 & 59137.000 & 25430.000 & & 0.011 & 0.116 \\
\hline 2001 & 35.506 & 0.078 & 62017.000 & 25230.000 & & 0.022 & 0.178 \\
\hline 2002 & 35.031 & 0.063 & 56523.000 & 28315.000 & & 0.067 & 0.264 \\
\hline 2004 & 29.084 & 0.072 & 61044.000 & 23227.000 & & 0.024 & 0.147 \\
\hline 2005 & 31.506 & 0.083 & 59307.000 & 8733.000 & & 0.027 & 0.149 \\
\hline 2006 & 33.573 & 0.082 & 58723.000 & 4399.000 & 6740.000 & 0.004 & 0.117 \\
\hline 2007 & 35.597 & 0.082 & 58235.000 & 3373.000 & 5550.000 & 0.005 & 0.127 \\
\hline 2008 & 27.910 & 0.080 & 56190.000 & 2946.667 & 7360.000 & 0.001 & 0.106 \\
\hline
\end{tabular}

Blank shows no data.

Source: The statistical yearbooks of the Yan'an City, the Annual Report on Chinese Soil Conservation, and Liu et al. (2007).

Table 2. The balance among afforestation, grain production, and water use in the Luo river basin

\begin{tabular}{|c|c|c|c|c|c|c|c|}
\hline & $\begin{array}{l}\text { Precipitation } \\
\left(\text { billion } \mathrm{m}^{3}\right)\end{array}$ & $\begin{array}{l}\text { Total ET from } \\
\text { main crops } \\
\text { (billion } \mathrm{m}^{3} \text { ) }\end{array}$ & $\begin{array}{c}\text { Planted area } \\
\text { of grain } \\
\text { (ha) }\end{array}$ & $\begin{array}{c}\text { Afforested area } \\
\text { (ha) }\end{array}$ & $\begin{array}{l}\text { Irrigated area } \\
\text { (ha) }\end{array}$ & $\begin{array}{l}\text { Sediment yield } \\
\text { (billion ton) }\end{array}$ & $\begin{array}{l}\text { Discharge } \\
\left(\text { billion } \mathrm{m}^{3} \text { ) }\right.\end{array}$ \\
\hline 1994 & 121.006 & 0.274 & 122198.000 & 24510.000 & 19680.000 & \multirow{4}{*}{0.080} & \multirow{4}{*}{0.848} \\
\hline 1995 & 76.439 & 0.272 & 125053.000 & 28150.000 & & & \\
\hline 1998 & 116.120 & 0.308 & 162569.000 & 40210.000 & & & \\
\hline 1999 & 82.829 & 0.290 & 128722.000 & 63910.000 & & & \\
\hline 2000 & & 0.272 & 119917.000 & 67870.000 & & 0.034 & 0.588 \\
\hline 2001 & & 0.196 & 94759.000 & 80640.000 & & 0.070 & 0.691 \\
\hline 2002 & & 0.172 & 84085.000 & 55321.000 & & 0.044 & 0.643 \\
\hline 2004 & & 0.215 & 89764.000 & 35224.000 & & 0.028 & 0.620 \\
\hline 2005 & & 0.207 & 87734.000 & 15073.000 & & 0.011 & 0.549 \\
\hline 2006 & & 0.218 & 89862.000 & 26546.000 & 25570.000 & 0.003 & 0.445 \\
\hline 2007 & 123.806 & 0.206 & 86007.000 & 10772.000 & 22430.000 & 0.009 & 0.581 \\
\hline 2008 & 93.626 & 0.212 & 81890.000 & 16874.733 & 23140.000 & 0.001 & 0.450 \\
\hline
\end{tabular}

Blank shows no data.

Source: The statistical yearbooks of the Yan'an City, the Annual Report on Chinese Soil Conservation, and Liu et al. (2007). 
basin is essential. Further observation of the afforested area is necessary to assess the effects of the afforested area on soil conservation during heavy rainfall.

The present study could not clarify the direct influence of afforestation on water resources due to the lack of data on the evapotranspiration rates of forests. Direct measurements of evapotranspiration in afforested areas should be performed to assess more precisely the balance among afforestation, grain production, and water use.

\section{Conclusion}

The balance among afforestation, grain production, and water use was improved by the Grain-for-Green-Policy in both the Yan and Luo river basins on the Chinese Loess Plateau. Climate change will increase the risks of water shortage and soil erosion during natural calamities such as droughts and floods. Therefore, further research is essential to maintain a harmonious balance between afforestation, grain production, and water use for achieving sustainable effects of soil conservation in the Chinese Loess Plateau.

\section{Acknowledgements}

This study was supported by JSPS KAKENHI Grant Number 24710055.

\section{References}

Fukushima, Y. and Taniguchi, M. eds. 2008. Water environmental issues of the Yellow River: Analyzing the cut-off of the Yellow River. Tokyo: Gakuhosha. (J)

Liu, J., Zehnder, A. and Yang, H. 2007. Historical trends in China’s virtual water trade. Water International 32: 78-90.

Matsunaga, K. 2013. Soil and water loss in China: History and a turning point in contemporary China. Tokyo: Keisoshobo. (J)

Oki, T. and Kanae, S. 2006. Global hydrological cycles and world water resources. Science 313: 1068-1072.

Sato, R., Nawata, H., Buhe, A., Nagasawa, R., Jia, R., Zhang, W., Hou, Q. and Yamanaka, N. 2008. Traditional land use in Loess Plateau (China) and the 'Grain-for-Green' project: A case from Ansai Province, Shaanxi. Bulletin of the Graduate School of Social and Cultural Studies, Kyushu University 14: 7-21.

Shi, N. 2001. Researches on historical geography in of the Loess Plateau. Zhengzhou: Yellow River Conservation Press. (C)

(J) written in Japanese

(C) written in Chinese 